\title{
Ethylene oxide sterilization in hospital practice
}

\author{
By M. A. R. FREEMAN \\ Clinical Assistant, Surgical Unit \\ AND C. F. BARWELL \\ Professor of Bacteriology, The London Hospital, E. 1
}

(Received 1 June 1960)

\section{INTRODUCTION}

Materials which cannot be sterilized by heat are being used increasingly in medicine, and their sterilization at the present time is not entirely satisfactory. Ethylene oxide is in use in the United States of America and in Sweden to produce sterility at room temperature, but so far it has only been used on a limited scale in hospitals in this country.

The literature on ethylene oxide is extensive and dates back to 1936 when Schrader and Bossert patented the use of alkylene oxides for killing 'pests and germs'. The variables upon which ethylene oxide sterilization depends have been investigated and reported by, among others, Phillips (1949), Kaye \& Phillips (1949) and Sykes (1958).

Following encouraging preliminary results (Barwell \& Freeman, 1959), this study was undertaken in order to develop a sterilizing technique and equipment for use in this country with a safe ethylene oxide mixture. We are indebted to the British Oxygen Research and Development Company for their great help in supplying the gas mixtures used and in advising upon the physical problems that arose, and to Messrs Allen and Hanbury for supplying the sterilizing chamber.

In this paper a gas mixture, sterilizing technique and equipment are described, and some clinical applications are briefly discussed. The gas mixture and the sterilizing equipment are now commercially available in this country.

The gas

Ethylene oxide is a three-ringed epoxy compound with the structural formula:<smiles>C1CO1</smiles>

It is a gas at room temperature since it boils at $10 \cdot 7^{\circ} \mathrm{C}$. At $30^{\circ} \mathrm{C}$. its vapour pressure is $1560 \mathrm{~mm}$. $\mathrm{Hg}$ and at $50^{\circ} \mathrm{C}, 2967 \mathrm{~mm}$. $\mathrm{Hg}$. It has been suggested (Phillips, 1958) that its bactericidal properties depend upon its power of alkylating proteins according to formula I (p. 338).

The great disadvantage of ethylene oxide as a sterilizing agent for routine hospital practice is that mixtures of ethylene oxide and air containing more than $3 \%$ of ethylene oxide are inflammable and if confined, explosive. This property 
necessitates the use either of special equipment to convey high concentrations of ethylene oxide to and from an evacuated sterilizing chamber or of mixtures of ethylene oxide with an inert gas to quench the explosive properties. The latter, cheaper solution does not require personnel trained in the use of explosive gases and accordingly has been used in this study.

Various gases have been used as the inert component of such mixtures. Amongst these are carbon dioxide, nitrogen and a mixture of 'Arcton 12' and 'Arcton 11'* (I.C.I. Ltd.). The Arctons, which are halogenated hydrocarbons having several other trade names, blanket the explosive properties of ethylene oxide as effectively as does carbon dioxide, but have the advantage of much lower vapour pressures because of their higher molecular weights. At $30^{\circ} \mathrm{C}$. Arcton 11 has a vapour pressure of $927 \mathrm{~mm}$. $\mathrm{Hg}$; Arcton 12, $5580 \mathrm{~mm} . \mathrm{Hg}$; carbon dioxide, $54,086 \mathrm{~mm}$. $\mathrm{Hg}$. For this reason ethylene oxide/Arcton mixtures were preferred because they contain more ethylene oxide per unit volume than do ethylene oxide/carbon dioxide mixtures at the same pressure.
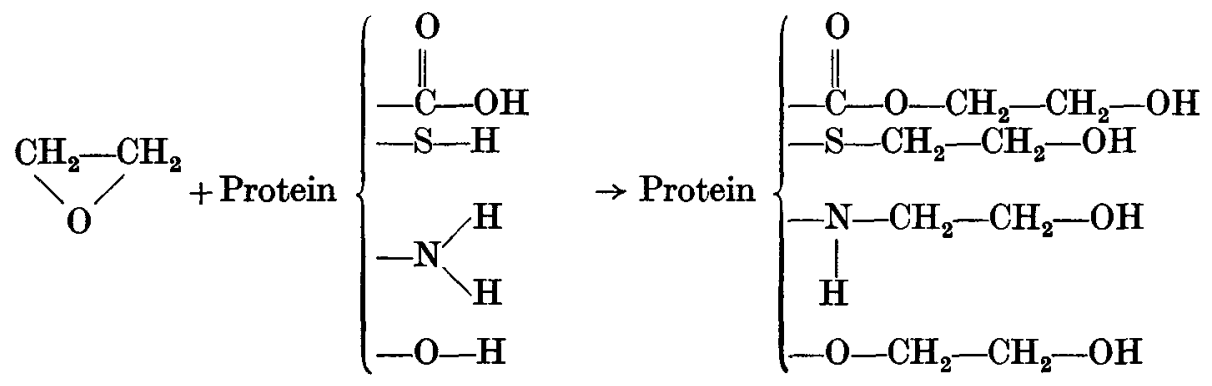

$\mathbf{I}$

A mixture of Arcton 12 and Arcton 11 (89\%) and ethylene oxide (11\%) is in use in the U.S.A., where it is marketed under the name of 'Cryoxide' (Registered trade mark American Sterilizer Company, Erie, Pa.). However, the boiling-point of Arcton $11,23.7^{\circ} \mathrm{C}$, is rather too close to room temperature to make Arcton 11/ethylene oxide mixtures convenient, although the low vapour pressure would be an advantage. In this study we have used a mixture of ethylene oxide $10 \%$ and Arcton 12,90\% by weight, which is a little easier to mix than Cryoxide and contains almost the same concentration of ethylene oxide in the vapour phase. Pending the establishment of a regular source of supply of ethylene oxide mixtures in the U.K., British Oxygen Gases Ltd. are prepared to make up individual cylinders to order. It is entirely non-explosive: lighted matches thrown into the gas are extinguished and no mixture of the combination with air is inflammable.

Arcton 12 is non-toxic, but ethylene oxide is toxic in both its liquid and vapour phases and in aqueous solution. Liquid ethylene oxide and solutions of it on the skin produced erythema and oedema (Sexton \& Henson, 1949). The first symptom noticed on over-exposure to ethylene oxide vapour is irritation to the nose and

* Throughout this paper the Arctons have been identified with the numbers with which they are designated under the current English numerical system. Until recently, however, Arcton 12 was known as Arcton 6 and Arcton 11 as Arcton 9. 
eyes. Delayed effects include nausea, vomiting and dizziness. Work on animals by Hollingsworth, Rowe, Oyen, McCollister \& Spencer (1956) has shown that exposure to higher concentrations leads to death from secondary respiratory infection. On the basis of this work it was suggested that in an atmosphere containing 50 p.p.m. ethylene oxide a man could work up to $8 \mathrm{hr}$. and probably not be affected. However, a recent report has stated that the substance is a powerful mutagenic agent (Gustafsson \& Ehrenberg, 1959).

In this study no special toxicity tests have been made, but the ethylene oxide in the sterilizing chamber has been released into a large but poorly ventilated room once or twice in $24 \mathrm{hr}$. with no apparent ill effect. It is obviously preferable that aerial contamination by the gas should be avoided by discharge from the chamber to the exterior and by adequate ventilation of the premises. Small quantities of the liquid mixture had no effect on the skin of one of the authors (M.A.R.F.) and it was found easy in practice to avoid contact with the liquid mixture during routine sterilization.

The following materials have been exposed to ethylene oxide vapour during this study and have not been affected by it: copper, steel, aluminium, brass, chromium, rubber, glass, perspex, nylon, polyvinyl chloride (P.V.C.), polythene, paper, wood and cotton. Paints, enamels, ink, Biro ink and pencil lead are also unaffected by it. The effect of liquid ethylene oxide has not been deliberately tested, but Perspex has been found to be damaged by it, so that precautions should be taken to prevent ethylene oxide in the liquid phase entering the sterilizing chamber (see Sterilizing Technique.

A number of materials, for example, rubber, have the property of taking up substantial quantities of ethylene oxide and Arcton which are slowly released after sterilization, and we have found P.V.C. to have this property. This effect can be undesirable in certain circumstances since, for example, bubbles of gas may appear in blood in P.V.C. tubing in use with pump-oxygenators. In Pl. 1, the formation of gas bubbles, presumably of Arcton 12, is shown. It has been found, by chemical analysis of washings, that ethylene oxide dissolved in P.V.C. can be entirely removed by exposing it to a vacuum of approximately $30 \mathrm{in} . \mathrm{Hg}$ for $1 \mathrm{hr}$. In hospital practice we have held such a vacuum for $2 \mathrm{hr}$. to provide a safety margin.

\section{The sterilizing chamber and related equipment}

Ethylene oxide/Arcton 12 mixtures are supplied by the British Oxygen Company in cylinders fitted with a dip-tube so that they should stand vertically when in use. We have used a standard autoclave as a sterilizing chamber. Any existing autoclave can easily be modified for use with ethylene oxide, without interfering with its continued use with steam, by introducing the gas through a T-piece in the steam inlet tube. A vacuum pump can be connected to the chamber in a similar way if necessary. In association with Messrs Allen and Hanbury, however, a chamber and ancillary equipment for use with ethylene oxide have been designed and will shortly be available commercially (Text-fig. 1).

The chamber must of course be gas-tight and should carry a compound gauge 


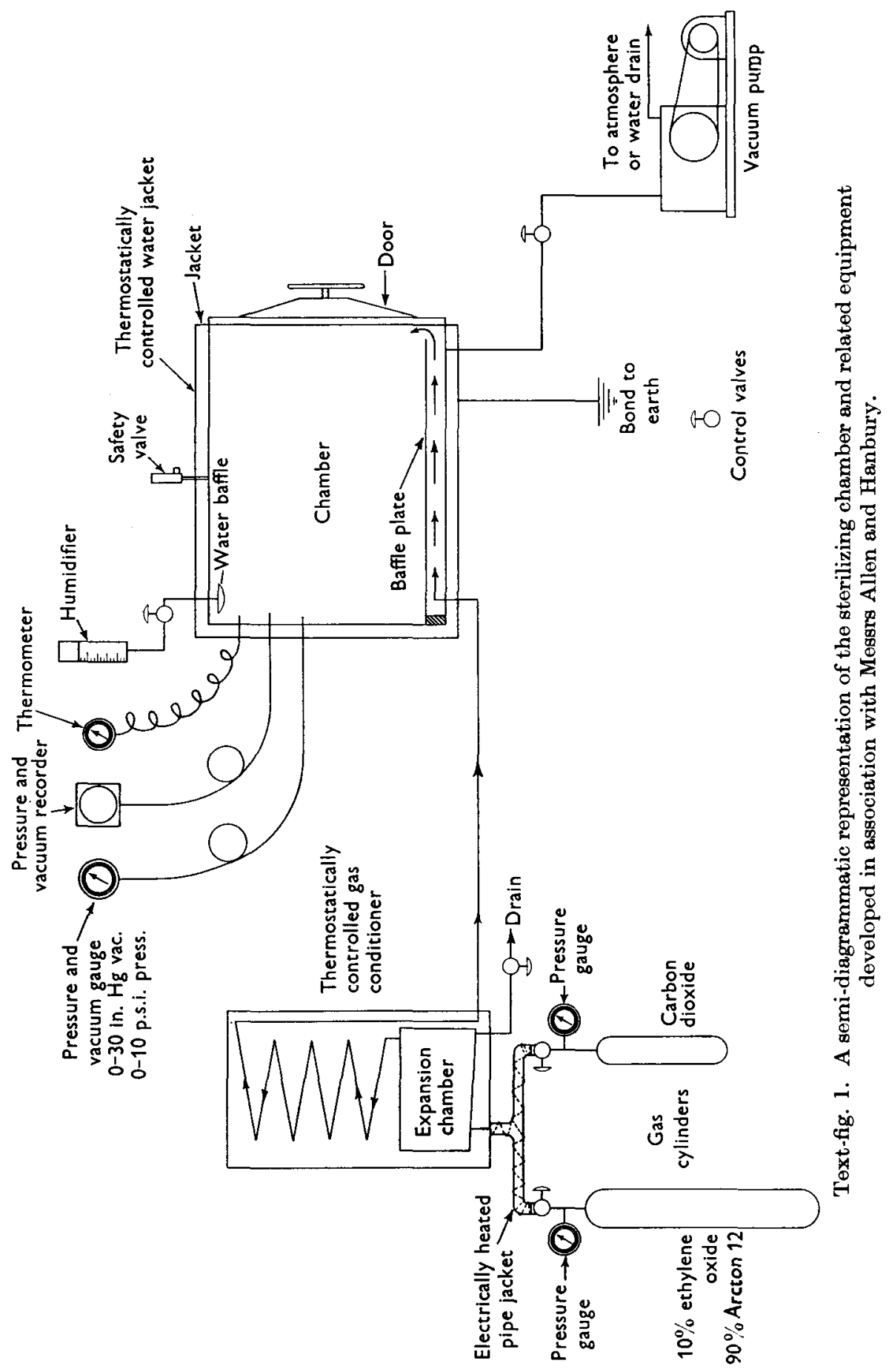


measuring from at least 0 to 10 pound per sq.in. (p.s.i.) pressure and $0-30 \mathrm{in}$. $\mathrm{Hg}$ vacuum. It can be surrounded by a heating jacket if it is desired to sterilize at above room temperature. The port through which the gas is introduced should be situated in the bottom of the chamber and should be shielded internally so that the gas is not injected directly on to the materials to be sterilized. This guards against the possibility of any ethylene oxide introduced as liquid coming in contact with equipment in the chamber. In the chamber of our apparatus a false bottom has been used to provide such a shield and, in order to raise the relative humidity during sterilization, provision has been made for the injection of a measured quantity of water after an initial vacuum has been drawn (see Sterilizing Technique).

The delivery tube from the gas cylinder to the chamber should pass through an expansion chamber and a heat exchanger consisting of a coiled copper tube immersed in hot water or steam, so that the emergent gases can be warmed and completely vaporized. A run-off tube may be provided at the bottom of the expansion chamber to trap the very small quantities of an oily impurity which the mixture occasionally contains.

Sterilization involves the drawing of a vacuum (see Sterilizing Technique) and this can be accomplished by a vacuum pump connected to the sterilizing chamber through a $\mathrm{T}$-piece in the gas delivery line or a separate port and line. The pump is also used to extract ethylene oxide from the chamber, and hence it should exhaust to the atmosphere or to a water drain. The vacuum pump is not damaged by the repeated passage of ethylene oxide through it. Provision should be made for connexion to the chamber of a cylinder of any non-toxic sterile gas such as carbon dioxide or nitrogen.

\section{Sterilizing technique}

The steps in the sterilizing technique are as follows:

(1) The chamber is brought up to the desired temperature. In this study a temperature of $30^{\circ}-40^{\circ} \mathrm{C}$. was used. (Higher temperatures would allow a shorter exposure time but were inappropriate in this study since heat-labile plastics were being sterilized.)

(2) The heat-exchanger is brought up to a temperature of approximately $100^{\circ} \mathrm{C}$. since the gases entering the heat-exchanger are cooled to well below room temperature as they leave the cylinder.

(3) The chamber is loaded.

(4) A vacuum of approximately $30 \mathrm{in}$. $\mathrm{Hg}$ is drawn.

(5) Water is introduced so as to yield a relative humidity of $30-50 \%$.

(6) The gas mixture is run into the chamber until a positive pressure of 5 p.s.i. is produced.

(7) The chamber is left closed for $14 \mathrm{hr}$.

(8) A second vacuum of approximately $30 \mathrm{in}$. $\mathrm{Hg}$ is drawn and held for $2 \mathrm{hr}$. to extract the ethylene oxide.

(9) The vacuum is replaced by any non-toxic sterile gas so that the chamber may be opened. For convenience we have used carbon dioxide, but filtered air would be as good. 
(10) The chamber is opened and the sterilized load removed.

This technique is safe and simple enough to be carried out by one man with no special training.

The purpose of most of the steps in this procedure is self-evident and needs no special comment. The drawing of an initial vacuum (step 4) is designed to empty the chamber of air so as to allow the final concentration of ethylene oxide to be as high as possible, but this is not essential since the air in the chamber can be removed by washing it out with the mixture. This procedure is expensive, however, and not as reliable a method as drawing a vacuum if the load is hollow and complex in shape. For sterilizing articles of simple shape in small containers, however, the 'washthrough' method is adequate.

Sterilization is most rapid at relative humidities between 30 and $50 \%$ (Kaye \& Phillips, 1949). Using the chamber described above, the introduction of a measured quantity of water into the chamber is possible after an initial vacuum has been drawn. In this way the relative humidity can be regulated but complete control is impossible unless the materials to be sterilized are perfectly dry and do not absorb water vapour. Where water injection is not possible a bowl of water can be placed in the chamber with the materials to be sterilized. If this is done, the bowl should contain a substantial quantity of water and the ethylene oxide mixture should be introduced immediately after the initial vacuum has been drawn since otherwise the water in the bowl may be entirely extracted. The exact amount of water is immaterial provided that an excess is used as shown by the presence of water in the bowl after sterilization. In practice about $200 \mathrm{ml}$. has been adequate for a $3 \frac{1}{2}$ cu.ft. chamber. The humidity requirements cannot, of course, be met by these means with sealed packages in water-proof plastic film.

Increases in pressure increase the amount of ethylene oxide in the chamber and hence reduce the exposure time necessary to produce sterility, since the exposure time is inversely related to the ethylene oxide concentration (Phillips, 1949). Maintaining high pressures for long periods, however, may not be easy if improvised chambers are being used and therefore, since the exposure time was to be measured in hours, a pressure of 5 p.s.i. was employed. At this pressure the gas mixture used contains $555 \mathrm{mg}$./ 1 . of ethylene oxide and produced sterility in $2-4 \mathrm{hr}$. This conforms with the finding of Phillips (1949). In practice a period of $14 \mathrm{hr}$. was used since this gave a wide safety margin and allowed convenient over-night treatment.

The minimum exposure time is approximately halved by a rise in temperature of $10^{\circ} \mathrm{C}$. (Phillips, 1949). Since, however, the object of this study was to sterilize heat-labile plastics, the temperature was kept between $30^{\circ}$ and $40^{\circ} \mathrm{C}$.

\section{Bacteriology}

The organisms against which ethylene oxide has been tested under the above conditions and the results are shown in Table 1.

Of the seven strains of bacteria tested, Bacillus subtilis was used in the form of dried 'spore-disks' supplied by the Southern Group Laboratories; all the other strains were first grown on solid media for 18-24 hr. and suspensions made in 
nutrient broth. At first throat swabs, moistened in the broth suspensions, were used but latterly suspensions dried in vacuo on filter-paper disks were found to be more convenient.

The strain of Micrococcus was included in these preparations because this organism was recovered from a number of 'spore-disks' in which exposure to ethylene oxide had effectively killed the $B$. subtilis spores. It was therefore regarded as possibly more resistant to the gas than the spores and it was later grown from the untreated blotting-paper used for making the test disks. The strain was

\section{Table 1. Effect of different periods of exposure to ethylene oxide on various organisms dried on filter-paper disks}

\begin{tabular}{lccc}
\multicolumn{1}{c}{ Organism } & 1 & 2 & 4 \\
Micrococcus & $40 / 55$ & $29 / 29$ & $10 / 10$ \\
Staphylococcus pyogenes & $40 / 44$ & $20 / 20$ & $9 / 9$ \\
Streptococcus pyogenes & $20 / 20$ & $10 / 10$ & N.D. \\
Escherichia coli & $19 / 19$ & $10 / 10$ & N.D. \\
Pseudomonas pyocyanea & $20 / 20$ & $10 / 10$ & N.D. \\
Bacillus stearothermophilus (spores) & $20 / 20$ & $10 / 10$ & N.D. \\
B. subtilis (spores) & $1 / 20$ & $4 / 9$ & $10 / 10$
\end{tabular}

Results shown as number of disks sterilized/number tested. N.D. = not done.

kindly investigated by Dr S. T. Cowan, Curator of the National Collection of Type Cultures, who reports that according to the classification of Shaw, Stitt \& Cowan (1951) it conforms with the species Staphylococcus lactis, and it is retained in the N.C.T.C. under no. 10,083. However, in the comparative tests shown in Table 1, where approximately $10^{6} \mathrm{~B}$. subtilis spores or $6 \times 10^{6} \mathrm{Micrococcus}$ per disk were used, the former preparation proved to be somewhat the more resistant.

\section{Packaging}

Equipment has been sterilized by ethylene oxide when packaged in the following materials : P.V.C., polythene and nylon film, cotton and linen cloth, cardboard and paper. A method for testing the penetration of P.V.C., for example, is shown in Pl. 2. The inside of the two test-tubes shown in this figure were smeared with the Micrococcus, and their mouths were then wired into either end of a length of P.V.C. tube of wall thickness $\frac{3}{16}$ in. Sterilization of the inside of such test-tubes (in $14 \mathrm{hr}$.) demonstrated penetration of the P.V.C. by ethylene oxide.

The ability of ethylene oxide to penetrate materials such as nylon film and its high diffusibility make the gas a convenient agent for sterilizing packaged equipment and, since plastic films are impermeable to bacteria, equipment packaged and sterilized in this way remains sterile indefinitely. However, these materials are only slowly permeable to air and consequently perfectly sealed packages of this material containing air may burst when exposed to the initial vacuum. A further theoretical hazard of the impermeability of these plastics to air, carbon dioxide, and perhaps to the Arctons, is that ethylene oxide, but not the blanketing gas, may 
diffuse into an air-containing package and there produce an explosive mixture. We have no definite information as to the permeability of these plastics to the Arctons but such information as we have suggests that they may be permeable: at all events explosions have never occurred in the sterilizing chamber in our experience and we cannot find a report of one in the literature. Nevertheless, for hospital, as against commercial, purposes cotton or linen cloths may be preferable to sealed plastics as packaging materials.

\section{Hospital application}

Advantage has been taken of the penetrating powers of ethylene oxide to sterilize an assembled heart-lung machine with the technique described above. Washings taken from the machine have always proved sterile and no clinical complications have been seen which might be referable to ethylene oxide or infection.

Other equipment that has been satisfactorily sterilized includes gum elastic, rubber and plastic urinary catheters, plastic skull prostheses, endoscopes, endotracheal tubes, Biro pens, blankets and amniotic membrane. At the time of writing it is proposed to sterilize a Geiger-Müller counter. Since ethylene oxide does not appear to damage any materials so far tested, it is reasonable to suppose that an even wider variety of equipment can be treated by this method.

The fact that ethylene oxide produces sterility at a physiological pressure, temperature and relative humidity suggests that it may be possible to sterilize biological materials with it. Our only experience in this connexion was the sterilization of amniotic membrane, and this was successful. Hufnagel (1954) has described a technique using ethylene oxide for the sterilization of arterial homografts. Whether ethylene oxide could be used routinely to sterilize living tissues remains to be seen but, from a consideration of the mode of action of the gas, it seems very improbable.

\section{CONCLUSION}

On the basis of the experimental and clinical evidence described above we regard ethylene oxide sterilization as being reliable, simple and safe, both for the personnel carrying out the procedure and for the patient. The long exposure period required makes the method appropriate for routine 'elective' sterilization rather than for rapid sterilization in emergency circumstances. This disadvantage is to some extent offset by the excellent penetrating powers of the gas which makes sterile packaging simple.

The method is more expensive and takes longer than does sterilization by autoclaving or dry heat, and the latter methods are therefore to be preferred for materials which can withstand heat. For those which cannot, however, the authors regard ethylene oxide sterilization as a satisfactory alternative.

\section{SUMMARY}

A non-explosive mixture of ethylene oxide and Arcton 12 is described. This mixture is now available commercially in this country. 


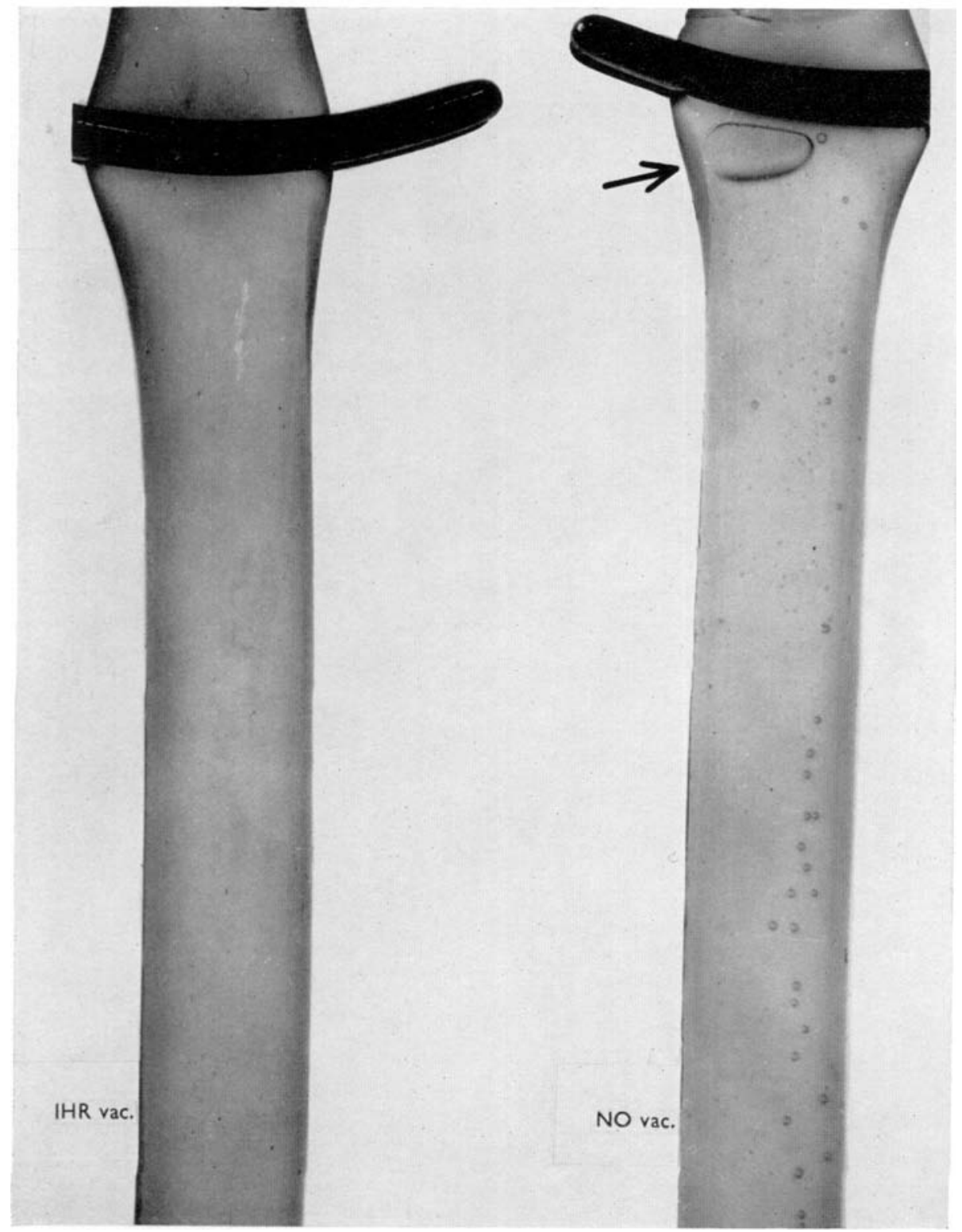




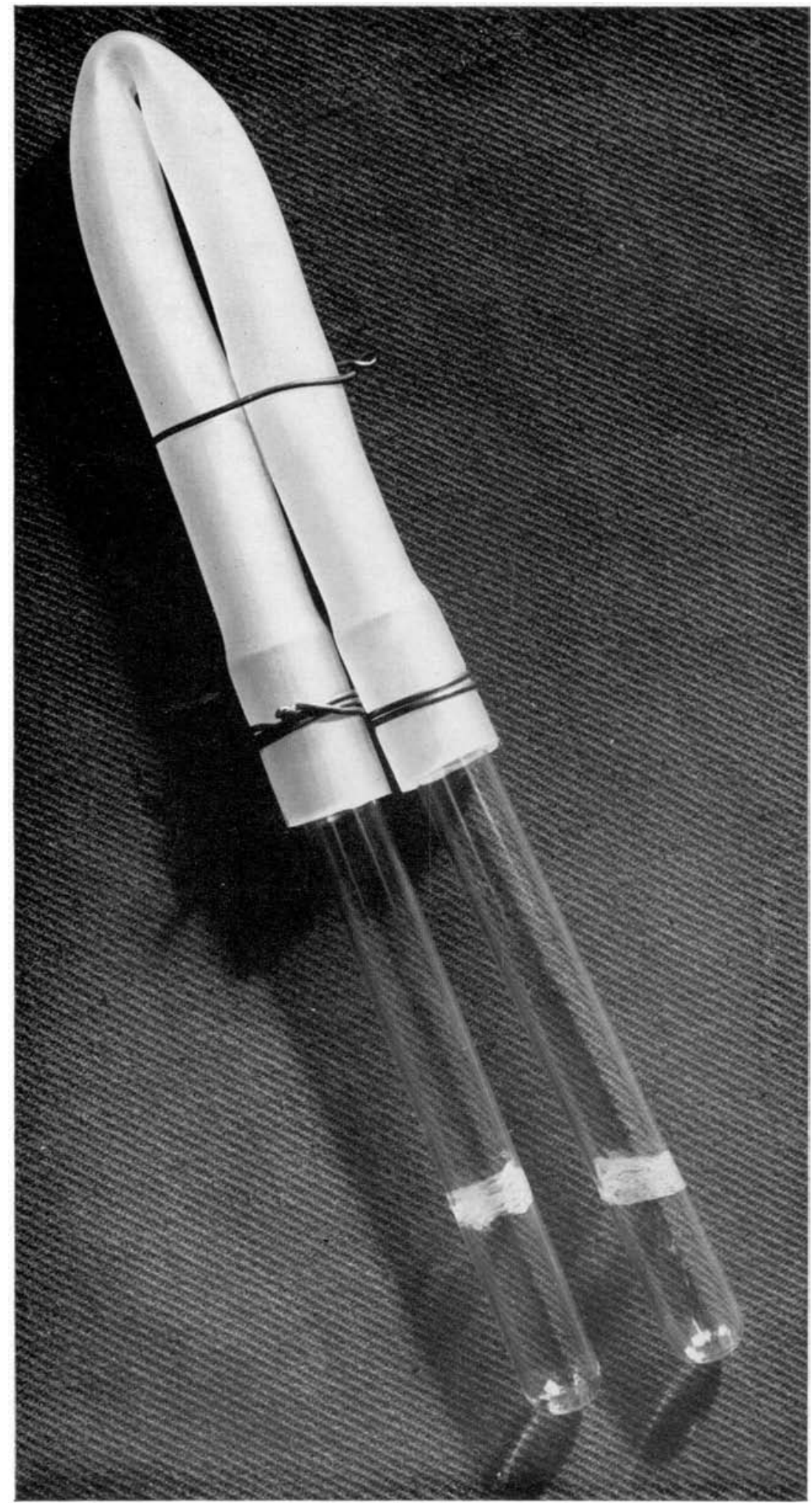

II. A. R. FREEMAN AND C. F. BARWELL 
A sterilizing chamber and related equipment for use with this gas and a sterilizing technique are also described.

Some applications of ethylene oxide sterilization are briefly discussed.

The authors would like to acknowledge the help and advice of Dr A. Bracken and Mr C. C. Wilton-Davies of the British Oxygen Research and Development Co. Ltd., Messrs Allen and Hanburys Ltd., Mr A. W. Aspinall and the staff of The London Hospital Instrument Department, and Mr J. G. Chapman, Senior Technician of the Department of Bacteriology, London Hospital.

\section{REFERENCES}

Barwell, C. F. \& Freeman, M. A. R. (1959). Sterilization by ethylene oxide. Lancet, i, 917. Gustafsson, A. \& Ehrenberg, L. (1959). Ethylene imine; a new tool for plant breeders. New Scientist, 5, 624.

Hollingsworth, R. L., Rowe, V. K., Oyen, F., McCollister, D. D. \& Spencer, H. C. (1956). Toxicity of ethylene oxide determined on experimental animals. A.M.A. Arch. industr. Hlth, 13, 217.

HufNaGeL, C. H. (1954). Method for preservation of arterial homo- and heterografts. Surg. Forum, Iv, 162.

KAYE, S. \& PhILlips, C. R. (1949). Sterilizing action of gaseous ethylene oxide; effect of moisture. Amer. J. Hyg. 50, 296.

Phillips, C. R. (1949). Sterilizing action of gaseous ethylene oxide; sterilization of contaminated objects with ethylene oxide and related compounds; time, concentration and temperature relationships. Amer. J. Hyg. 50, 280.

PhILLIPs, C. R. (1958). Gaseous sterilization. First Annual Series, Becton, Dickinson Lectures on Sterilization, p. 31.

Schrader, H. \& Bossert, E. (1936). U.S. Pat. 2,037,439.

Sexton, R. J. \& Henson, E. V. (1949). Dermatological injuries by ethylene oxide. J. industr. Hyg. 31, 297.

Shaw, C., StiTt, J. E. \& Cowan, S. T. (1951). Staphylococci and their classification. J. gen. Microbiol. 5, 1010.

Sykes, G. (1958). Disinfection and Sterilization, p. 177. London: E. \& F. N. Spon Ltd.

\section{EXPLANATION OF PLATES}

\section{Plate 1}

Two identical pieces of P.V.C. tubing exposed to a mixture of $10 \%$ ethylene oxide and $90 \%$ Arcton 12 for 14 hours. The tube on the right was not subsequently subjected to a vacuum while that on the left was exposed to a vacuum of approximately $30 \mathrm{in}$. $\mathrm{Hg}$ for $\mathrm{l} \mathrm{hr}$. Both tubes were then filled with water and clamped. Gas bubbles can be seen collecting in the tube that was not subjected to a vacuum.

\section{Plate 2}

The interior of these test-tubes previously smeared thickly with the Micrococcus have been sterilized in ethylene oxide demonstrating penetration of the P.V.C. tubing by the gas. 